\title{
Sexual dimorphism in insulin resistance in a metabolic syndrome rat model
}

\author{
Myrian Velasco', Rosa Isela Ortiz-Huidobro', Carlos Larqué², Yuriko Itzel Sánchez-Zamora', José Romo-Yáñez ${ }^{3}$ and \\ Marcia Hiriart ${ }^{1}$ \\ ${ }^{1}$ Neuroscience Division, Department of Cognitive Neuroscience, Instituto de Fisiología Celular, Universidad Nacional Autónoma de México, \\ Mexico City, Mexico \\ Department of Embryology and Genetics, Facultad de Medicina, Universidad Nacional Autónoma de México, Mexico City, Mexico \\ ${ }^{3}$ Department of Gynecological and Perinatal Endocrinology, Instituto Nacional de Perinatología 'Isidro Espinosa de los Reyes', Mexico City, Mexico
}

Correspondence should be addressed to M Velasco or M Hiriart: mvelasco@ifc.unam.mx or mhiriart@ifc.unam.mx

\begin{abstract}
Objective: We assessed the sex-specific differences in the molecular mechanisms of insulin resistance in muscle and adipose tissue, in a MS rat model induced by a high sucrose diet.

Methods: Male, female, and ovariectomized female Wistar rats were randomly distributed in control and high-sucrose diet (HSD) groups, supplemented for 24 weeks with $20 \%$ sucrose in the drinking water. At the end, we assessed parameters related to MS, analyzing the effects of the HSD on critical nodes of the insulin signaling pathway in muscle and adipose tissue.

Results: At the end of the treatment, HSD groups of both sexes developed obesity, with a 15,33 and $23 \%$ of body weight gain in male, female, and OVX groups respectively, compared with controls; mainly related to hypertrophy of peripancreatic and gonadal adipose tissue. They also developed hypertriglyceridemia, and liver steatosis, with the last being worse in the HSD females. Compared to the control groups, HSD rats had higher IL1B and TNFA levels and insulin resistance. HSD females were more intolerant to glucose than HSD males. Our observations suggest that insulin resistance mechanisms include an increase in phosphorylated AKT(S473) form in HSD male and female groups and a decrease in phosphorylated P70S6K1(T389) in the HSD male groups from peripancreatic adipose tissue. While in gonadal adipose tissue the phosphorylated form of AKT decreased in HSD females, but not in HSD males. Finally, HSD groups showed a reduction in $\mathrm{P}-\mathrm{AKT}$ levels in gastrocnemius muscle.

Conclusion: A high-sucrose diet induces MS and insulin resistance with sex-associated differences and in a tissue-specific manner.
\end{abstract}

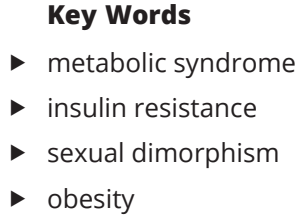

Endocrine Connections (2020) 9, 890-902

\section{Introduction}

Morphological and physiological differences associated with sex are common in animals (1), many of them depend on gonadal hormones and sex chromosomes (2). Men and women differ in metabolism and energy balance (3). However, the mechanisms that explain the sex differences in response to obesity, metabolic syndrome (MS), and type 2 diabetes mellitus (DM2) are not well understood (4). It is essential to clarify the effect of sex on the incidence of these diseases and offer effective strategies for their prevention and treatment.

MS is a group of metabolic alterations that increases the risk of developing cardiovascular diseases (CVD) and DM2. The definitions for MS may vary; but according to WHO, the cardinal signs include central obesity

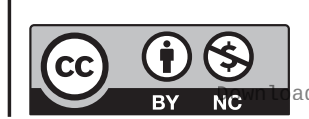

This work is licensed under a Creative Commons Attribution-NonCommercial 4.0 International License. ded from Bioscientifica.com at 04/26/2023 11:31:24AM 
(based on the waist circumference), dyslipidemia (decreased levels of high-density lipoprotein cholesterol, or hypertriglyceridemia), hypertension, impaired fasting glucose, and insulin resistance (5). MS diagnosis involves the presence of 3 or more of these signs, including insulin resistance or impaired fasting glucose. The International Diabetes Federation (IDF) mentions central obesity as a cardinal sign (6). Other consider the BMI as necessary (7).

The MS develops in response to hypercaloric diets and sedentary lifestyles, depending on the personal genetic and environmental factors. Other factors, such as geography, age, race, education, income, and sex, had contributed to the increase in its prevalence to a pandemic proportion $(8,9)$. Sex-associated differences in MS components and their prevalence have been observed among men and women (9).

Adipose tissue is differently distributed between men and women, depending on genetic, hormonal, and social factors (10). For example, men show an android phenotype, where fat accumulates predominantly in visceral adipose tissue; while women have a gynoid phenotype, with a higher proportion of subcutaneous adipose tissue $(11,12)$.

Obesity often associates with insulin resistance, where a low-grade inflammatory state exists. There is a high level of pro-inflammatory adipokines, such as IL1B, TNFA, and IL6 $(13,14,15)$, and alterations in the storage of nutrients. Triglycerides and free fatty acids released in excess produce ectopic lipid accumulation in various tissues (muscle, liver, pancreas, and heart). Both mechanisms negatively affect insulin signaling, reducing insulin sensitivity, and producing metabolic abnormalities $(16,17)$.

After insulin binding, its receptor is autophosphorylated and activates several downstream targets such as IRS1 and kinases such as PI3K, and AKT, which are critical nodes in the insulin signaling pathway (18). PI3K/ AKT pathway regulates glucose uptake, glycogen synthesis, gluconeogenesis, protein and lipids synthesis, and cell growth. AKT activity is regulated by phosphorylation on Thr-308 and Ser-473 by PDK1, and mTORC2, respectively. These critical nodes are potential targets of several kinases that down-regulate the insulin pathway (19). Under conditions of nutrient overload, the increase in protein S6 kinase 1 (P70S6K1) levels in human visceral adipose tissue participates in the development of insulin resistance and inflammation (20). An overactivation of P70S6K1, via mTORC1, results in the phosphorylation of IRS1 on serine residues, inhibiting its binding to the insulin receptor, promoting its proteasomal degradation, and ultimately downregulating AKT downstream signaling (21).
Insulin resistance (IR) shows an impairment of fasting glucose (IFG) and glucose tolerance (IGT), both of which have a dimorphic sex pattern. Compared to women, IFG in men is more frequent, while IGT is more common in women (22). However, the molecular mechanisms that underlie the sex differences in insulin resistance are not fully understood.

In this study, we determined sex differences in the molecular mechanisms of insulin resistance, by assessing the levels of the phosphorylated and total forms of IRS1, AKT and P70S6K1 in adipose tissue and the gastrocnemius muscle in a MS model, induced with a high-sucrose diet in male and female rats.

\section{Material and methods}

We obtained reagents as follows: HEPES, oil red-O, EGTA and collagenase from Merck; many antibodies from Cell Signaling Technology (CST), and others will be mentioned in the text.

\section{Animals}

All methods used in this study were approved by the Animal Care Committee of the Instituto de Fisiología Celular (IFC), Universidad Nacional Autónoma de México (UNAM), Mexico City. Animal care was performed according to the 'International Guiding Principles for Biomedical Research Involving Animals', Council for International Organizations of Medical Sciences, 2010.

\section{MS model}

Young adult Wistar rats (250-280 g, approximately 8 weeks of age) males, females and ovariectomized females (OVX) were obtained from the local facility of the IFC, UNAM, Mexico City. OVX rats underwent a bilateral ovariectomy through a lumbar incision before dietary treatment was administered. Ovariectomy was performed when rats were $200 \mathrm{~g}$ of body weight. The OVX rats started the treatment when they reached 250-280 g of weight. Rats were randomly separated in control and HSD groups and housed in $12 \mathrm{~h}$ light:12 h darkness cycle, at $20-23^{\circ} \mathrm{C}$ and $40 \%$ of relative humidity.

All animals were fed with standard rat chow (Lab Diet 5001 ) composed by $28.5 \%$ protein, $13.5 \%$ fat, and $58 \%$ carbohydrates. Tap water or $20 \%(\mathrm{w} / \mathrm{v})$ sucrose solution was provided to the control group or to the HSD

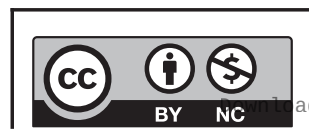

This work is licensed under a Creative Commons Attribution-NonCommercial 4.0 International License. ded from Bioscientifica.com at 04/26/2023 11:31:24AM 
(high-sucrose diet) group ad libitum, respectively, for 24 weeks as described previously (23).

All measurements and experiments were done in $12 \mathrm{~h}$ fasted-rats, during this period the sucrose solution was replaced with plain water. At the end of treatment, animals were anaesthetized with an intraperitoneal (IP) injection of sodium pentobarbital (40 mg/kg). Blood samples were obtained from the inferior cava vein in heparinized tubes. Peripancreatic (pWAT) and gonadal (gWAT) white adipose tissue samples, gastrocnemius muscles and liver were dissected. Animals were euthanized using pentobarbital overdose (100-150 mg/kg).

We quantified food and water consumption by rat per day. Food consumption decreased in HSD groups which was $7.0 \pm 0.4,11.4 \pm 0.3$ and $11.8 \pm 0.3 \mathrm{~g}$ for female, OVX, and male respectively; and $18.7 \pm 0.2,26.6 \pm 0.4$ and $23.6 \pm 0.3 \mathrm{~g}$ for the control female, OVX, and male groups, respectively. In contrast, beverage consumption increased in HSD groups $(86 \pm 1,108 \pm 2$ and $86 \pm 2 \mathrm{~mL}$ for female, OVX and male), compared with the control groups $(57 \pm 2,66 \pm 0.1$ and $48 \pm 1 \mathrm{~mL}$ for female, OVX and male, respectively). Global caloric intake increased in the HSD group. Table 1 shows the daily caloric intake for control and HSD rats ( $n=12$ rats for female and male; $n=6$ for OVX rats) and the respective percentage, according to the nutrient group.

\section{ITT (insulin tolerance test) and IPGTT (IP glucose tolerance test)}

We performed the ITT or IPGTT (12 $\mathrm{h}$ fasted-rats) 1 week prior to the end of treatment. IP insulin $(0.2 \mathrm{IU} / \mathrm{Kg}$ of body weight) or glucose (2 $\mathrm{g}$ glucose $/ \mathrm{kg}$ of body weight) injection was administered to each rat. The same person handled the animals. Peripheral blood samples were collected from the tail vein immediately before glucose or insulin administration (time 0) and 15, 30, 60, 90 and $120 \mathrm{~min}$ after. Glucose levels were determined with a glucometer (Accu-Check, Hoffman La Roche Basel Switzerland).

\section{Somatometric parameters}

After 24 weeks of treatment, we obtained the following measures: body weight (BW, g), abdominal circumference (AC, circumference of abdomen just above the iliac crest, $\mathrm{cm})$ and body length (BL, animal length from the tip of the nose to the anus, cm) $(23,24)$.

\section{Liver steatosis}

For liver histological examination, we used liver pieces from the right ventral lobe which were fixed in a $4 \%$ paraformaldehyde-PBS solution, embedded in paraffin, cut and stained with standard hematoxylin-eosin protocol. Oil red O stain (Merck) was used to determine lipids accumulation in frozen liver sections, fixed in a $4 \%$ paraformaldehyde-PBS solution before the staining procedure. All tissue slices were imaged with a DM500 compound microscope (Leica Microsystems), using a 40X objective.

\section{Protein extraction and Western blot}

We obtained a pool of total protein extracts (three rats each) from gastrocnemius, pWAT and gWAT, by homogenization in RIPA lysis buffer. Total protein was quantified by Bradford's method. The protein extracts were separated by SDS-PAGE and transferred to a PVDF membrane, using an accelerated semi-dry blotting transfer system (Trans blot turbo, Bio-Rad Laboratories). The membranes were blocked with 5\% non-fat dry milk in TBS-tween $1 \%$ for $1 \mathrm{~h}$ at room temperature and incubated overnight at $4^{\circ} \mathrm{C}$ with rabbit polyclonal anti-AKT (CST\#9272) diluted 1:500; rabbit polyclonal anti-p-AKT(S473) (CST\#9271) diluted 1:500; rabbit polyclonal anti-P70S6K1, rabbit polyclonal anti-p-P70S6K (T389) diluted 1:200 (CST\#cat9202 and \#cat9205) or rabbit polyclonal anti-IRS1 or rabbit polyclonal anti-pIRS1(S1101) diluted 1:200 (CST\#2382 and CST\#2385) in blocking solution. Goat polyclonal antibody against beta actin (Santa Cruz Technology \#sc1616) was used

Table 1 Nutrimental distribution and daily caloric intake.

\begin{tabular}{|c|c|c|c|c|}
\hline \multirow[b]{2}{*}{ Nutrients } & \multicolumn{2}{|c|}{ Male (kcal/day/rat) } & \multicolumn{2}{|c|}{ Female (kcal/day/rat) } \\
\hline & Control & MS & Control & MS \\
\hline Carbohydrates & $55.6(57.9 \%)$ & $99.1(82.7 \%)$ & $42.8(57.8 \%)$ & $84.5(87.6 \%)$ \\
\hline Proteins & $27.5(28.5 \%)$ & $12.8(11.6 \%)$ & $21.2(28.7 \%)$ & $7.94(8.2 \%)$ \\
\hline Fat & $13.9(13.4 \%)$ & $6.5(5.5 \%)$ & $9.9(13.4 \%)$ & $3.7(3.4 \%)$ \\
\hline Total & $96.0 \pm 1.4(99 \%)$ & $119.5 \pm 2.6(99 \%)^{a}$ & $73.9 \pm 0.9(99 \%)$ & $96.2 \pm 2.6(99 \%)^{b}$ \\
\hline
\end{tabular}

\begin{tabular}{|c|c|}
\hline \multicolumn{2}{|c|}{$\mathbf{O V X}$ (kcal/day/rat) } \\
\hline Control & MS \\
\hline $62.1(57.2 \%)$ & $115.8(87.9 \%)$ \\
\hline $31.1(28.7 \%)$ & $13.3(9.9 \%)$ \\
\hline $14.5(13.4 \%)$ & $6.2(4.6 \%)$ \\
\hline $107 \pm 0.4(99 \%)$ & $135 \pm 0.6(99 \%)^{a, c}$ \\
\hline
\end{tabular}

${ }^{a} p<0.001,{ }^{b} P<0.02$ compared to their control, $c P<0.01$ compared to HSD male and female groups.

https://ec.bioscientifica.com

https://doi.org/10.1530/EC-20-0288 (c) 2020 The authors Published by Bioscientifica Ltd

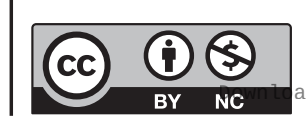

This work is licensed under a Creative Commons Attribution-NonCommercial 4.0 International License. ded from Bioscientifica.com at 04/26/2023 11:31:24AM via free access 
to detect beta actin as a load control. After incubation with the secondary antibodies, proteins were visualized using a chemiluminescent HRP substrate method with Immobilon Western Chemiluminescent HPR substrate (\#WBKLSO100, Merck Millipore). Densitometric analysis was performed using ImageJ software (NIH 1.44) and represents an average of the intensity of bands of three independent experiments.

\section{Analysis of plasma cytokines}

Plasma samples were collected from the inferior cava vein in heparinized tubes, from $12 \mathrm{~h}$ fasted control and HSD rats. The plasma levels of TNFA, IL1B, IL6 and IL4 all from Peprotech were determined by ELISA according to the manufacturer's instructions. Optical density (OD) was measured after 15 min using an ELISA reader (Multiskan FC Microplate Photometer, Thermo Scientific) at $405 \mathrm{~nm}$.

\section{Systolic blood pressure}

Systolic blood pressure (SBP) was measured with the Panlab non-invasive blood pressure (NIBP) system (LE 5002, Panlab Harvard Apparatus). Rats were trained in several sessions before the SBP and cardiac frequency measurements, which were done with heated and awake rats. We performed an average of four measurements/ day/rat. Normal systolic blood pressure was considered between 110-135 mmHg; while above $140 \mathrm{mmHg}$ was considered hypertension.

\section{Metabolic parameters}

Plasma insulin levels were determined using Ultrasensitive rat insulin ELISA system according manufacturer's instructions (10-1137-10; Mercodia Uppsala, Sweden). Triglycerides were determined by colorimetric glycerol phosphate oxidase and phenol 4-amine anti-pyrene peroxidase (GOP-PAP) method, using a Random RX Imola, according manufacturer's instruction (TR 3823, Randox Laboratories Limited, United Kingdom).

\section{Statistical analysis}

All data are reported as the mean \pm S.E.M.; $n$ denotes the number of animals analyzed. For statistical analysis, twoway ANOVA (with sex and diet as factors) and one-way ANOVA with post hoc Tukey's tests were performed (Origin 2016 software). Statistical significance was considered for $P$ values $<0.05$.

\section{Results}

\section{HSD leads to obesity}

To study the effect of a high-sucrose diet (HSD) on body weight, we quantified the body weight during the 24 weeks of treatment in males $(n=65$, for control and HSD groups), females ( $n=24$ for control and HSD groups), and OVX rats ( $n=12$ for control and HSD groups). After 24 weeks of treatment, HSD groups gained more body weight (BW) than the controls (Fig. 1A left panel). Furthermore, BW was different between male and female. Interestingly, the percentage of BW gain (Fig. 1A right panel) compared to control group in females started on the 3rd week of treatment and increased to 33\% until the end, compared to controls (Fig. 1B). Concerning the males, the difference between $\mathrm{BW}$ was evident from the 8 th week, and at the end of treatment, BW gain was only $15 \%$ higher compared to controls. The OVX rats showed a middle behavior between the others, with a BW gain of $23 \%$ higher compared to controls (Fig. 1A right panel).

The BW gain was associated with an increase in the size of fat depots. Compared to controls, peripancreatic and gonadal adipose depots were heavier in HSD. The increase in peripancreatic fat depot weights were 135, 195 and $350 \%$ for male, female and OVX groups respectively. Meanwhile for gonadal adipose tissue they corresponded to 145,248 and $169 \%$ for male, female and OVX groups, respectively (Fig. 1C). Although no changes in length between control and HSD rats of male and OVX groups were observed, there were differences between control and HSD female rats. Figure 1D shows other parameters, such as abdominal circumference (AC) and BMI, that were higher in the HSD groups compared to their controls. In addition all the aforementioned parameters were different between males and females.

\section{Insulin resistance}

We performed an intraperitoneal glucose tolerance test (IPGTT, Fig. 2A) or an insulin tolerance test (ITT, Fig. 2B) in $12 \mathrm{~h}$ fasted rats, one week before the end of the treatment. The glucose tolerance test showed that (Fig. 2A), HSD rats had higher blood glucose levels following the glucose injection, compared to their counterparts. However, HSD females showed a maximum glucose level of $370 \pm 17 \mathrm{mg} / \mathrm{dL}$, while males had $294 \pm 25 \mathrm{mg} / \mathrm{dL}$ at 15 min. In the HSD groups, blood glucose did not return to basal levels after $120 \mathrm{~min}$. Quantification of area under the curve (AUC) showed an increase in both HSD female and male rats. Besides, control females showed a higher 
A
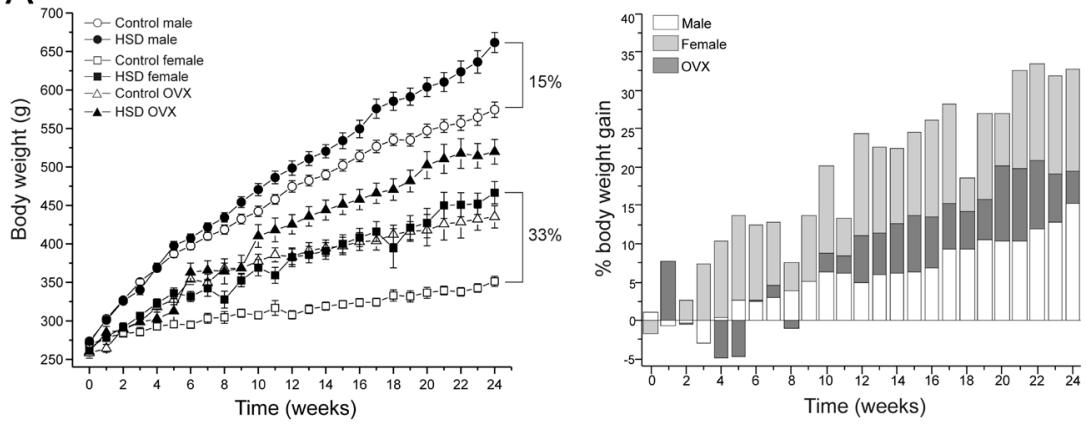

B
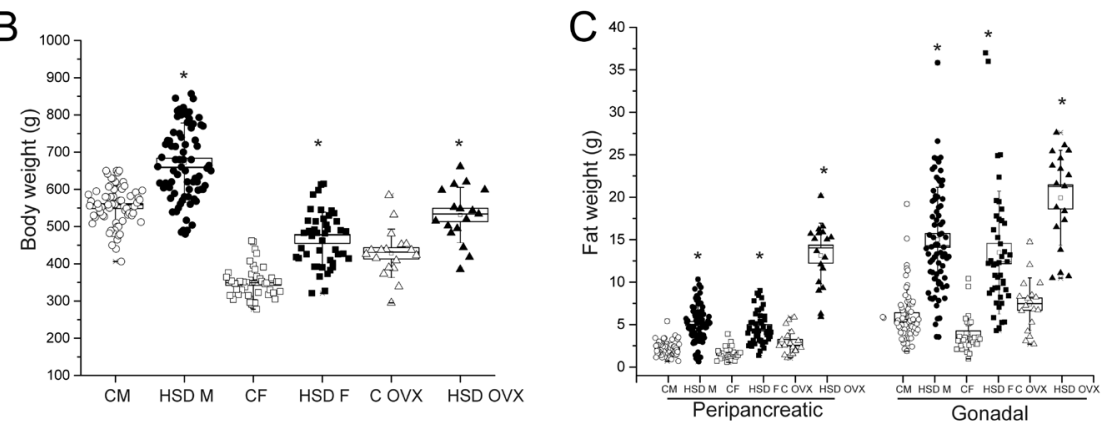

D

\begin{tabular}{|c|c|c|c|c|c|c|}
\hline & \multicolumn{2}{|c|}{ Male } & \multicolumn{2}{|c|}{ Female } & \multicolumn{2}{|c|}{ ovx } \\
\hline & Control & HSD & Control & HSD & Control & HSD \\
\hline Length $(\mathrm{cm})$ & $26.3 \pm 0.1$ & $26.5 \pm 0.08$ & $23.3 \pm 0.2$ & $24.0 \pm 0.1^{*}$ & $23.2 \pm 0.2$ & $23.6 \pm 0.2$ \\
\hline $\begin{array}{l}\text { bdominal } \\
\text { ircumference }(\mathrm{cm})\end{array}$ & $22.3 \pm 0.2$ & $25.1 \pm 0.2^{*}$ & $18.4 \pm 0.3$ & $21.9 \pm$ & $20.5 \pm 0.5$ & $23.05 \pm 5^{*}$ \\
\hline $\mathrm{MI}\left(\mathrm{Kg} / \mathrm{m}^{2}\right)$ & $8.01 \pm 0.07$ & $9.5 \pm 0.2^{*}$ & $6.5 \pm 0.08$ & $8.1 \pm 0.2^{*}$ & $7.9 \pm 0.5$ & $9.4 \pm 0.2^{*}$ \\
\hline
\end{tabular}

area under the curve (AUC Fig. $2 \mathrm{~B})$ than males $(P<0.01)$. The HSD OVX rats did not show any difference compared to their control group (data not shown).

In the ITT (Fig. 2C), HSD groups were less sensitive to insulin when compared to control groups, depicted by an increment in the AUC (Fig. 2D). Moreover, HSD males showed a higher AUC than females $(P<0.007)$. These observations indicate that females are more glucose intolerant, while males are less sensitive to insulin.

\section{Metabolic changes}

We analyzed some metabolic parameters to determine the effect of a high sucrose diet on the fasting insulin, glucose and triglycerides (TG) plasma levels. HSD rats of both sexes were hyperinsulinemic (Fig. 3A) compared with their controls $(P<0.0001)$. However, HSD males showed higher insulin levels compared to HSD females. Furthermore, only the HSD male group showed hyperglycemia $(P<0.02)$ (Fig. 3B). TG levels were higher in HSD groups of both sexes, compared to their controls (Fig. 3C), although females and OVX rats showed higher

\section{Figure 1}

High-sucrose diet produces obesity. (A) Body weight gain after 24 weeks of diet (left panel) and the percentage of BW gain compared to control (right panel) in control and HSD male $(n=65$, for control and HSD groups), female ( $n=24$, for control and HSD groups) and ovariectomized rats (OVX; $n=12$, for control and HSD groups). (B) Body weight at the end of HSD treatment mean \pm S.E.M. Two-way ANOVA was performed (Sex, $\mathrm{F}(1,228)=380.9$, and diet, $\mathrm{F}(1,228)=122.6$, $P=0.0001$ for both factors), with post hoc Tukey's test, $* P<0.0001$ compared to their control groups, ${ }^{*} P<0.0001$ compared to control male group, boxes around the mean represent the S.E.M., and whiskers represent the S.D. (C) Peripancreatic and gonadal adipose tissue weight of males ( $n=63$ to control and $n=75$ to HSD), females ( $n=29$ and 44 for control and HSD respectively) and OVXs ( $n=18$ for both conditions), boxes around the mean represent the S.E.M., and whiskers represent the S.D. Two-way ANOVA was performed $(\operatorname{Sex}, F(1,208)=3.8$ and $\mathrm{F}(1,207)=5.5 ; P=5.2 \times 10^{-2}$ and $P=0.019$ for pWAT and gWAT respectively; Diet, $\mathrm{F}(1,208)=158.9$ and $\mathrm{F}(1,207)=143.3 ; P=0.0001$ for pWAT and gWAT respectively), with post hoc Tukey's test, $* P<0.0001$ compared to their control group. (D) Somatometric parameters mean \pm S.E.M. for length, abdominal circumference (AC) and BMI. Two-way ANOVA was performed (Sex, $\mathrm{F}(1,225)=595.9,207.5$ and $106.7 ; P=0.0001$ for length, AC and BMI, respectively) with post hoc Tukey's test. $* P<0.0001$ compared to their control groups. levels in both, controls and HSD conditions, compared to males.

Concerning to the systolic blood pressure (SBP) (Fig. $3 \mathrm{D})$, only HSD males had hypertension $(P<0.008)$. We did not observe changes in cardiac frequency in any group (Fig. 3E).

\section{Morphometric profile of adipose tissue}

We also analyzed the effect of HSD in the morphometric profile of peripancreatic (pWAT) and gonadal (gWAT) white adipose tissue; we analyzed the adipocyte diameter in pWAT (Fig. 4A) and gWAT (Fig. 4B). We observed that adipocyte diameter of all HSD groups increased compared to controls. The frequency distribution of adipocyte diameters from both depots in the HSD animals shifted to the right (insert on the right in Fig. $4 \mathrm{~A}$ and B. In addition, the frequency of larger adipocytes (diameter from 106 to $226 \mu \mathrm{m}$ ) in pWAT of HSD females was higher than in HSD males.

Adipocytes of HSD OVX rats showed larger diameters than female and male groups, at the peak frequency

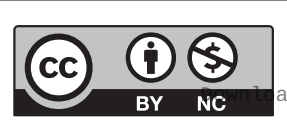


A

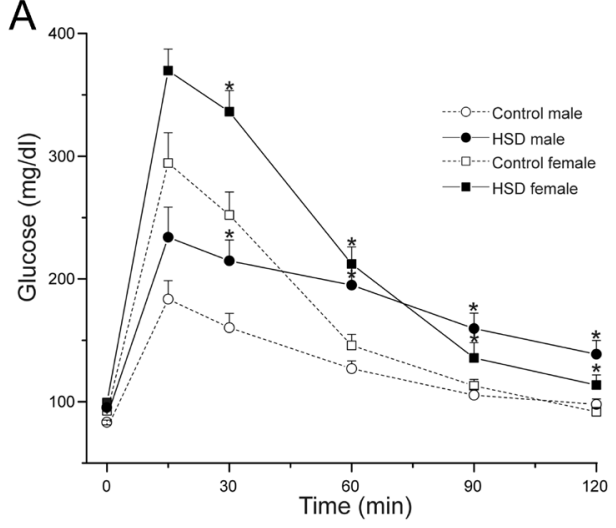

C

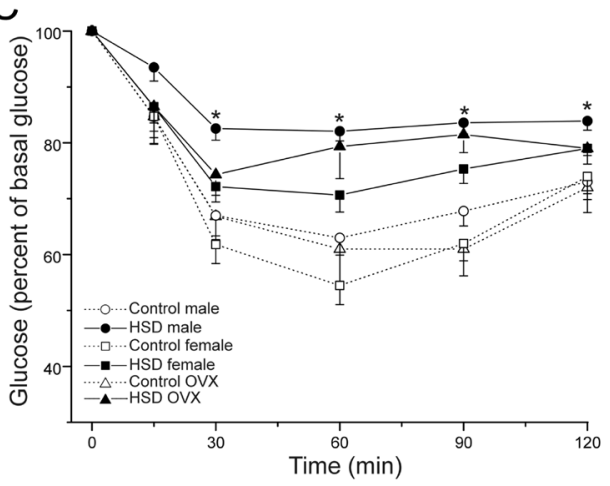

B

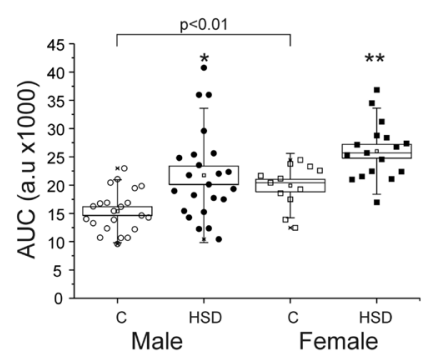

D

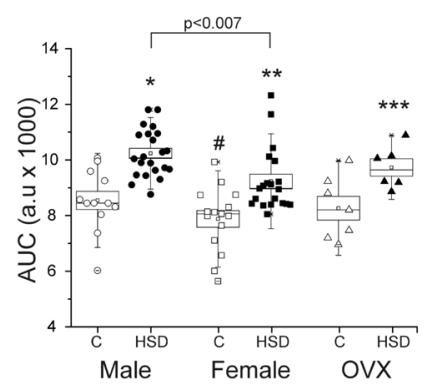

Figure 2

Sex differences in insulin resistance. (A) IP glucose tolerance test ( $2 \mathrm{~g} / \mathrm{kg}$ body weight) were performed in male ( $n=22$ and 23 to control and HSD group respectively), female ( $n=22$ for both conditions) control and HSD rats. Data expressed as mean \pm S.E.M. Two-way ANOVA was performed $($ Sex, $F(1,70)=10.4, P=0.0018$ and diet $\left.\mathrm{F}(1,70)=20.8, P=2.04 \times 10^{-5}\right)$, with post hoc Tukey's test $* P<0.001, * \star P<0.02$ compared to their controls. (B) The areas under the curves (AUC) $* P<0.001, * \star P<0.02$ compared to their control group, boxes around the mean represent the S.E.M., and whiskers represent the SD. (C) Insulin ( $0.2 \mathrm{IU} / \mathrm{Kg}$ body weight) was administered IP to males ( $n=12$ and 22 to control and HSD group respectively), females ( $n=17$ to control group and $n=20$ to HSD group) and OVXs ( $n=7$ to both conditions). Data expressed as mean \pm S.E.M., $* P<0.01$ compared to their controls. (D) AUC boxes around the mean represent the S.E.M., and whiskers represent the S.D. Two-way ANOVA was performed (Sex, $\mathrm{F}(1,32)=25.4, P=1.77 \times 10^{-5}$ and diet $\left.\mathrm{F}(1,32)=18.4, P=1.53 \times 10^{-4}\right)$, with post hoc Tukey's test. $* P<0.05 ; * \star P<0.01 ; * \star \star P<0.02$.
(106-126 $\mu \mathrm{m})$ in gonadal adipose tissue. In addition, the mean adipocyte diameter increased by 15,30 , and $40 \%$ in HSD males, females, and OVXs, respectively, compared to their controls in peripancreatic adipose tissue. In contrast, these changes were lower in gonadal adipose tissue (Fig. 4C).

\section{The cytokine profiles}

We determined the change in the cytokine secretion profile associated to adipocyte hypertrophy. We measured plasma levels of IL1B (Fig. 5A) and observed a four-, five-, and four-fold increment in HSD males, females, and OVX groups, respectively, in HSD rats compared to controls. Moreover, IL1B levels were higher in HSD females compared to HSD males $(P<0.02)$. Plasma levels of TNFA (Fig. 5B) also increased 9 times in males, and 2 times in females, and OVXs fed with HSD. Interestingly, TNFA levels were undetectable in the OVX control groups. We did not find differences in IL6 and IL4 plasma levels among any of HSD groups compared to their controls (Fig. 5C and D).

\section{HSD leads to liver steatosis}

We observed that the liver weight of HSD male $(18.2 \pm 0.7 \mathrm{~g})$ was heavier than their HSD females counterparts $(12.2 \pm 0.4 \mathrm{~g})$ and HSD OVXs $(13.3 \pm 0.7 \mathrm{~g})$ $(P<0.04)$. However, after normalization using total body weight, the ratio liver weight/BW decreased in HSD female and HSD male groups compared to their controls (Fig. 6A) $(P<0.03)$. No differences were observed between the OVX groups.

Histological analyses showed microvesicular fat depositions (black arrow heads, Fig. 6B). Moreover we analyzed lipids accumulation (Fig. 6C), by using Oilred-O staining, and observed that all HSD groups showed (Fig. 6D), an increase in the percentage of the area occupied by lipids in HSD groups compared to control groups. However, lipids accumulation in HSD groups from female and OVX groups were higher than HSD male group.

\section{Effect of HSD in insulin signaling}

We analyzed the IR mechanisms induced by HSD by measuring the total protein and phosphorylated forms of IRS1, AKT, and P70S6K1 in pWAT, gWAT, and the gastrocnemius muscle. We observed higher levels of total IRS1 in both pWAT and gWAT of HSD groups (males, females, and OVX) compared to their controls (Fig. 7A and B); while phosphorylated IRS1(S1101) was not detected (original Western blots for pWAT and gWAT are shown in

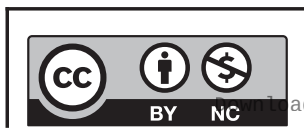

This work is licensed under a Creative Commons Attribution-NonCommercial 4.0 International License. ded from Bioscientifica.com at 04/26/2023 11:31:24AM via free access 


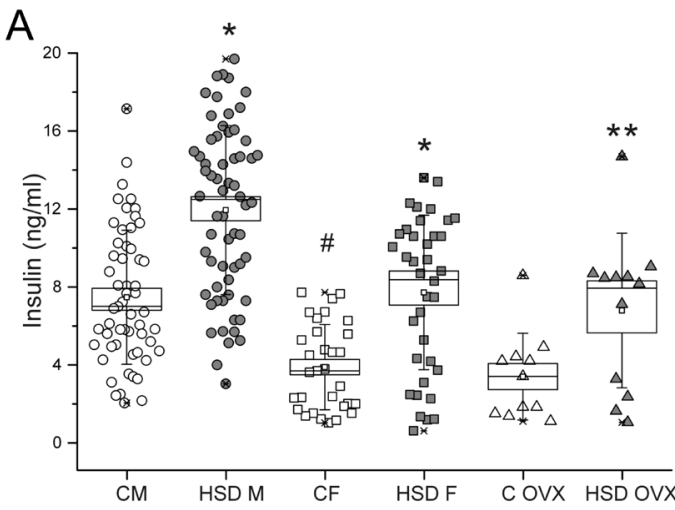

B

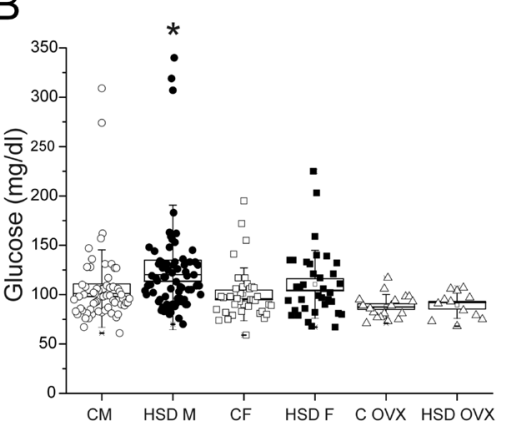

D

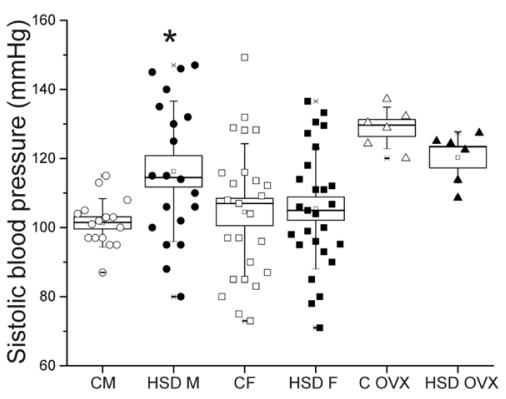

C

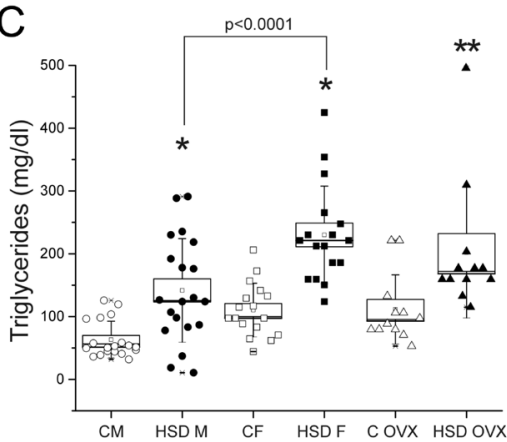

E

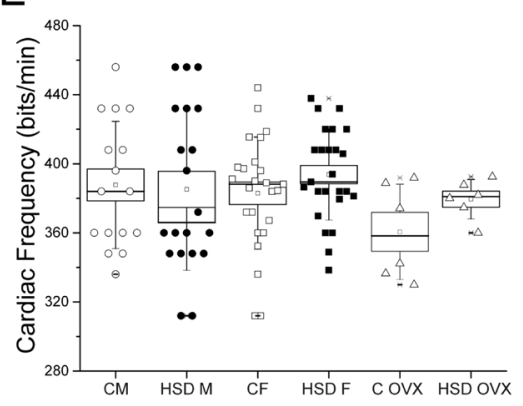

Figure 3

High-sucrose diet affects the metabolic status. (A) Plasma insulin levels from male $(n=60)$, female $(n=34)$ and OVX $(n=12)$ group of both conditions. Two-way ANOVA was performed (Sex, $\mathrm{F}(1,183)=47.5, P=8.57 \times 10^{-11}$ and diet $\left.F(1,183)=53.7, P=7.11 \times 10^{-12}\right)$, with post hoc Tukey's test $* P<0.0001, * \star P<0.02$ compared to their control group, ${ }^{\#} P<0.0001$ compared to control males, boxes around the mean represent S.E.M. and whiskers represent the S.D. (B) Plasma glucose levels from male $(n=70)$, female $(n=36)$ and OVX groups $(n=12)$. Boxes around the mean represent the S.E.M., and whiskers represent the S.D. Two-way ANOVA was performed (Sex, $\mathrm{F}(1,208)=2.865, P=0.09$ and $\operatorname{diet} \mathrm{F}(1,208)=5.517$, $P=0.02)$, with post hoc Tukey's test * $P<0.02$. (C) Plasma triglycerides levels from males $(n=20)$, females ( $n=17)$ and OVX rats $(n=12)$ of both conditions. Boxes around the mean represent the S.E.M., and whiskers represent the S.D. Two-way ANOVA was performed $(\operatorname{Sex}, F(1,69)=21.255$, $P=1.79 \times 10^{-5}$ and diet $\mathrm{F}(1,69)=45.449$ $\left.P=3.89 \times 10^{-9}\right)$, with post hoc Tukey's test $\star P<0.001, * * P<0.01$ compared to control groups, ${ }^{\#} P<0.01$ compared to control male. systolic blood pressure (D) and cardiac frequency (E) from males $(n=20)$, females $(n=25)$ and OVX rats $(n=6)$ for both conditions. boxes around the mean represent the S.E.M., and whiskers represent the s.D. one-way ANOVA was performed with post hoc Tukey's test $* P<0.008$ compared to control groups.
Supplementary Figs 3, 4, 5, 6, 7, 8 and 9, see section on supplementary materials given at the end of this article).

Furthermore, we observed increased levels of phosphorylated AKT(S473) in pWAT of HSD males and HSD females, while OVXs did not show differences. Instead, the levels of phosphorylated P70S6K1(T389) decreased in pWAT of HSD males and HSD OVX, compared to their controls, while the HSD female group did not show differences compared to control group (Fig. 7A and B). In gonadal adipose tissue, we observed decreased levels of phosphorylated AKT(S473) in HSD female group compared to control group; while we did not observe differences in p-AKT(S473) and p-P70S6K1(T389) between HSD groups and their controls (Fig. 7C and D).

Moreover, we analyzed the same proteins in gastrocnemius muscle and observed a reduction in
p-AKT(S473) levels of HSD males and HSD females (Fig. 8A), compared to their controls (Fig. 8B); while in OVX no differences between HSD and controls groups were found. Finally, p-P70S6K1(T389) levels did not show any change between HSD groups and controls (original Western blots for pWAT and gWAT are shown in Supplementary Figs 10, 11 and 12).

\section{Discussion}

We compared the MS development in response to a HSD administration for 24 weeks, in males and female adult rats. We observed an interesting markedly dimorphic response in BW gain and metabolic parameters. Furthermore, HSD male rats were less insulin sensitive, while HSD female rats were more intolerant to glucose. https://ec.bioscientifica.com https://doi.org/10.1530/EC-20-0288 (c) 2020 The authors Published by Bioscientifica Ltd
This work is licensed under a Creative Commons Attribution-NonCommercial 4.0 International License. ded from Bioscientifica.com at 04/26/2023 11:31:24AM via free access 

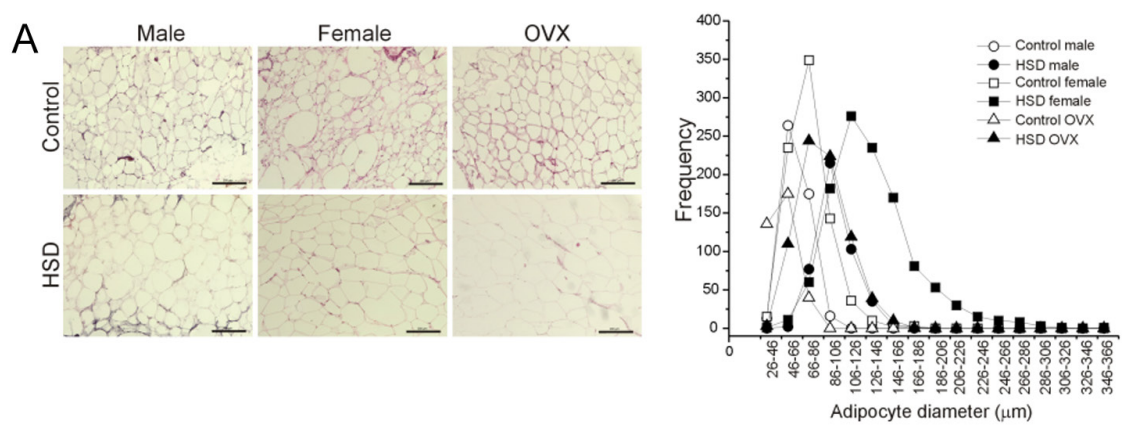
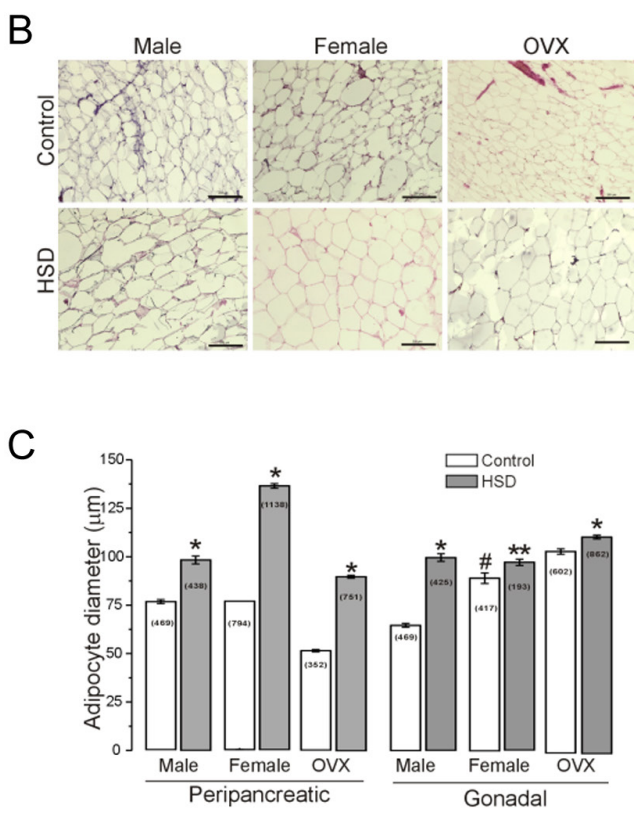

\begin{abstract}
Figure 4
High-sucrose diet produces hypertrophy of the peripancreatic and gonadal adipocytes. Representative picture of H\&E stained sections $(n=6$ animals per group and 10 optic fields per animal) from peripancreatic (A), and gonadal adipose tissue (B), the insert represent the frequency histogram of adipocyte diameters (classified in 17 classes from 26-46 $\mu \mathrm{m}$ to 346-366 $\mu \mathrm{m}$ ). (C) The bars represent the mean \pm S.E.M. of adipocytes diameter for both adipose tissue depots from male, female and OVX rats of both conditions ( $\mathrm{n}$ is indicated in the bars). Two-way ANOVA was performed (Sex, $\mathrm{F}(1,2835)=409.3$ and $\mathrm{F}(1,1500)=10.3 ; P=0$ and $P=0.0013$ for $\mathrm{pWAT}$ and gWAT respectively; Diet, $F(1,2835)=1714.6$ and $F(1,1500)=69.0 ; P=0$ and $P=2.2 \times 10^{-16}$ for PWAT and gWAT respectively), with post hoc Tukey's test; with interaction between sex and diet. $* P<0.0001, * * P<0.03$ compared to the control group, ${ }^{\#} P<0.0001$ compared to the control male group. 10x objective, scale bar $=200 \mu \mathrm{m}$.
\end{abstract}

We assessed the molecular mechanisms of insulin resistance in adipose tissue and muscle by measuring the levels of phosphorylated AKT on serine 473 and phosphorylated P70S6K1 on threonine 389, which are activated by insulin signaling. We found that the p-AKT(S473) form in pWAT were higher in both HSD female and male groups, compared to their controls. However, AKT downstream signaling was altered in the HSD male and OVX groups, revealed by a decreased levels of the p-P70S6K1(T389). In addition, p-AKT(S473) levels decreased in gWAT from HSD females, compared to controls, without differences in male and OVX groups. Finally, p-AKT(S473) in gastrocnemius muscle was decreased in both HSD female and male groups.

Sex-associated differences were previously observed in the MS components (9). After 24 weeks of treatment, high sucrose diet induced obesity in male and female rats. However, male rats in all conditions were heavier than their female counterparts. Interestingly, HSD produced a higher BW gain in females (by 33\%), compared to their controls. The body fat in women is more abundant than in men, irrespective of ethnicity, BMI, or age (25).
These differences are related to an estrogenic effect (26). Premenopausal women tend to accrue more subcutaneous gluteal-femoral fat; where subcutaneous adipocytes have more TG storage capacity and expandability. Whereas men accrue more visceral fat in the upper body region, which shows more lipolytic activity that contributes to cardiovascular risk $(12,26,27,28)$.

Obesity does not depend on BW, but on either a raise in adipocyte number (hyperplasia) or an enhanced fat accumulation, which increases the size of adipocytes (hypertrophy) (29); and while women develop hyperplasia, men adipocytes suffer hypertrophy. During obesity, visceral adipose tissue exceeds its storage capacity and it is characterized by adipocyte hypertrophy, tissue fibrosis, and inflammation which includes the release of free fatty acids (FFAs) and several pro-inflammatory adipokines (reviewed in (9)). These mediators induce inflammation in other tissues $(15,30,31)$. We observed that pWAT and gWAT adipocytes from HSD male, female, and OVX rats, increased in size (hypertrophy) in association with an increase in plasma IL1B and TNFA levels. Surprisingly, we did not observe differences in IL6 between HSD and controls. 

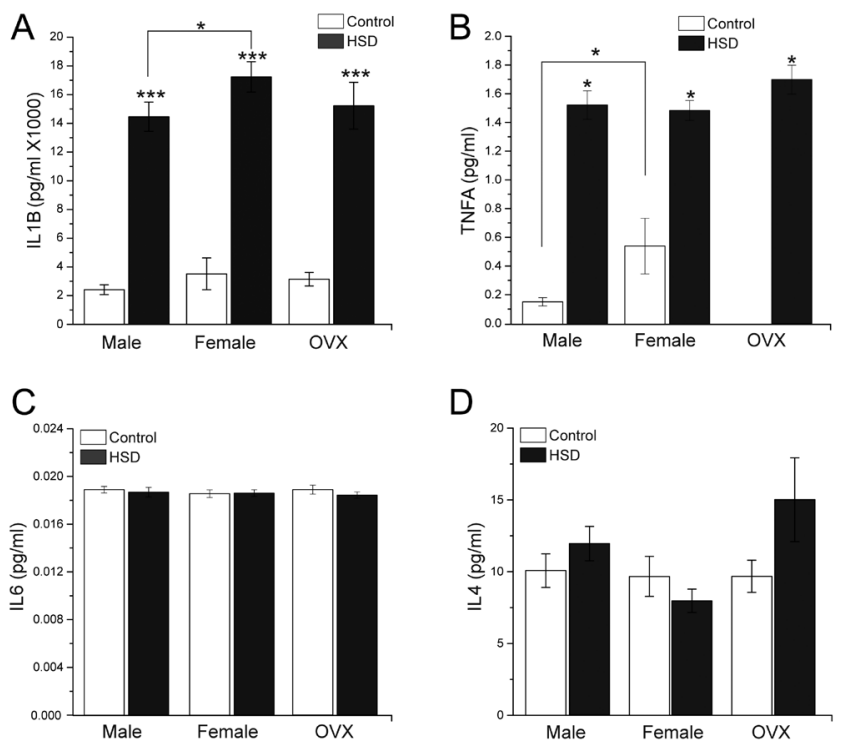

\section{Figure 5}

Cytokines profile. (A) Plasma IL1B levels of male, female and OVX control and HSD groups (two-way ANOVA was performed (Sex, $F(1,271)=9.167$, $P=0.0027$ and diet $F(1,271)=165.325, P=0)$, with post hoc Tukey's test $\star P<0.02, * * \star P<0.0001$ compared to control). (B) Plasma TNFA levels of male, female and OVX control and HSD groups (two-way ANOVA was performed $(\operatorname{Sex}, \mathrm{F}(1,67)=3.1593, P=0.080$ and $\operatorname{diet} \mathrm{F}(1,67)=134.46, P=0)$, with post hoc Tukey's test * $P<0.001$ compared to control). (C) Plasma IL6 levels of male, female and OVX control and HSD groups. (D) Plasma IL4 levels of male, female and OVX control and HSD groups. We used $n=25$ per duplicated for each cytokine. The bars represent the mean \pm S.E.M.

However, as several factors affect IL6 secretion, their effects probably result in down-regulation in our model.

To investigate the hormone effect on the metabolic syndrome components, we used ovariectomized rats.
Several pieces of evidence suggest that ovarian hormones, like estrogens, are involved in body weight regulation $(9,32,33)$, increase food intake and energy expenditure (34). Moreover, estrogens also participate in adiposity distribution, triglycerides storage capacity, and particularly in the liver regulation of lipids metabolism and serum lipoproteins (VLDL-triglycerides, LDL, HDL-cholesterol) levels (reviewed in (35)).

We observed that the control OVX group showed an increased body weight gain of $23 \%$ at the end of the treatment compared with control females, suggesting a protective role of estrogens against obesity. Furthermore, the HSD OVX group showed the same increase (23\%) at the end of the treatment compared with the control OVX group, suggesting that a HSD and estrogens have the same impact over body weight gain.

Furthermore, HSD OVX rats showed an increase in liver fat accumulation in both HSD female and HSD OVX rats. In contrast, female control rats showed the lowest liver fat accumulation. All these changes could also be related to estrogen actions. Previous studies with ovariectomized animal models observed an increase in liver fat accumulation, dyslipidemia, insulin resistance $(35,36)$.

Interestingly, blood pressure and glucose homeostasis, in which a significant regulatory role of estrogens has been suggested, did not show changes. These components showed similar levels between the OVX group and the female control group. With respect to glucose homeostasis, an explication could be related to estrogen actions through G-protein-coupled estrogen receptor (GPER) as
A
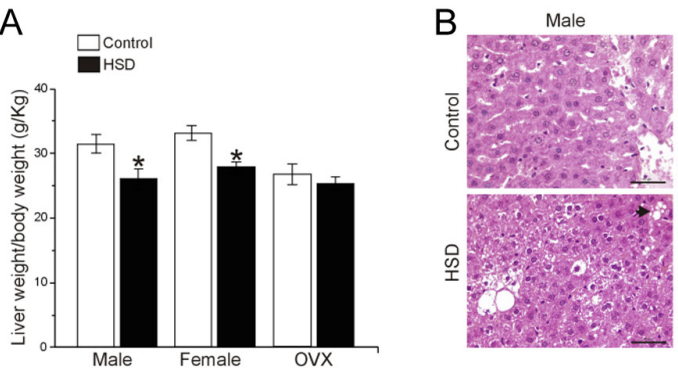

C

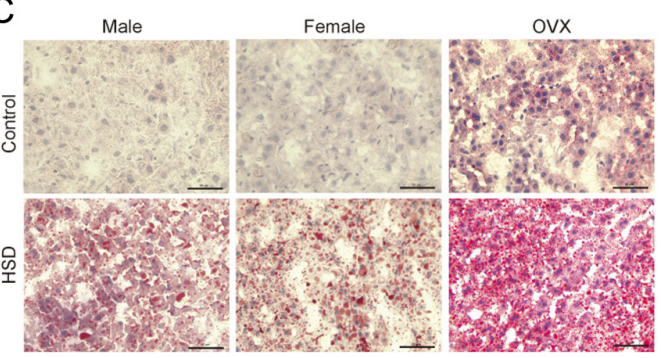

Female

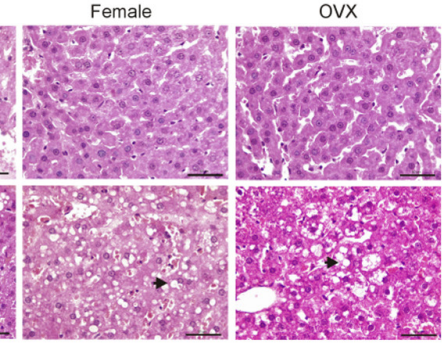

D

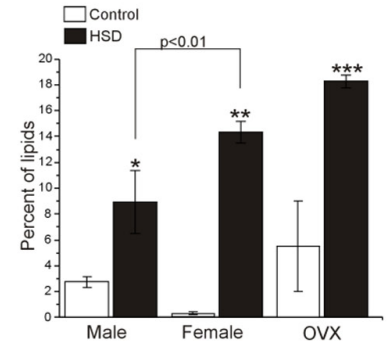

Figure 6

Liver steatosis. (A) The ratio of the liver weight and body weight ratio of the rats. The bars represent the mean \pm S.E.M. $(n=10)$. Two-way ANOVA was performed $(\mathrm{Sex}, \mathrm{F}(1,39)=1.81$, $P=0.1857$ and diet $\left.\mathrm{F}(1,39)=17.01, P=1.88 \times 10^{-4}\right)$, with post hoc Tukey's test * $P<0.03$ compared to control. Representative pictures of H\&E stained (B) and Oil-red-O stained, black arrowheads show microvesicular fat depositions (C) liver sections from males, females and OVXs of control and HSD conditions, scale bar $=50 \mu \mathrm{m}$. (D) The bars represent the percentage of area occupied by lipids in both control and HSD conditions from male, female and OVX groups ( $n=10$ rats per condition). Two-way ANOVA was performed (Sex, $F(1,35)=1.80, P=0.18$ and diet $\left.\mathrm{F}(1,35)=81.30, P=1.18 \times 10^{-10}\right)$, with post hoc Tukey's test; with interaction between sex and $\operatorname{diet}(P=0.001)$. $* P<0.002, * * P<0.0001$; $\star \star \star P<0.05$ compared to their control group. https://ec.bioscientifica.com https://doi.org/10.1530/EC-20-0288 (c) 2020 The authors Published by Bioscientifica Ltd

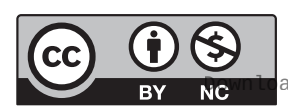

This work is licensed under a Creative Commons Attribution-NonCommercial 4.0 International License. ded from Bioscientifica.com at 04/26/2023 11:31:24AM 
A
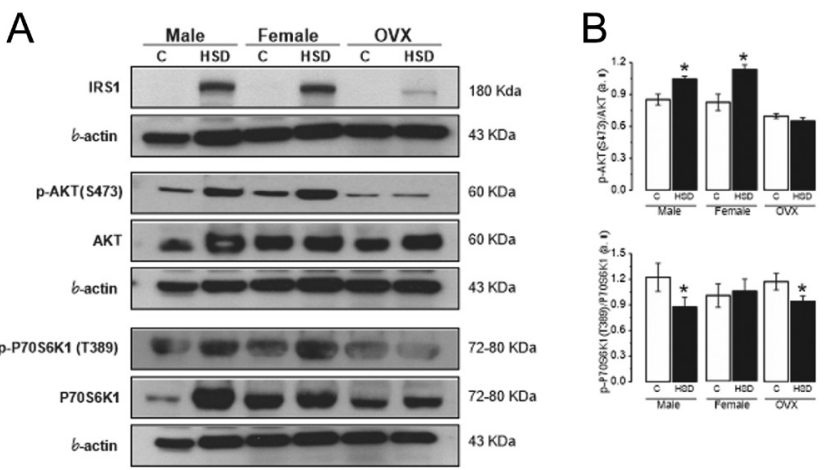

C

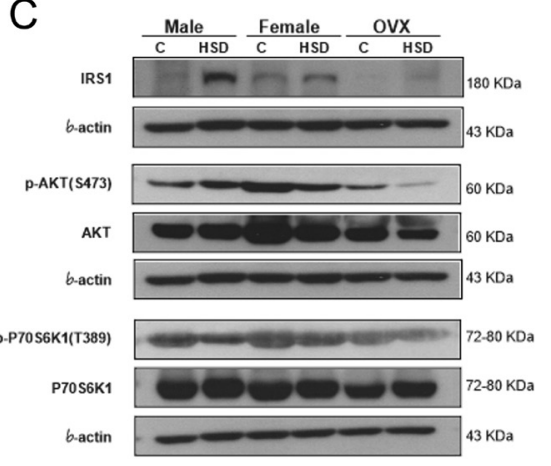

D

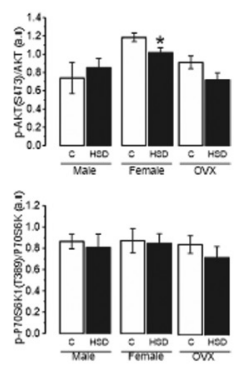

Figure 7

Effect of high-sucrose diet over the insulin-signaling pathway in peripancreatic and gonadal adipose tissue. Representative blots of IRS1, AKT, p-AKT(S473), P70S6K1, p-P70S6K1(T389), and $\beta$-actin as load control, from pooled peripancreatic adipose tissue (pWAT) (A) and gonadal adipose tissue (gWAT) (C) from control and HSD groups. Normalized ratio of phosphorylated AKT and P70S6K1 and total forms in PWAT (B) and gWAT (D). Mean density \pm S.E.M. from three independent experiments. Two-way ANOVA was performed for p-AKT (Diet $\mathrm{F}(1,8)=22.4, P=0.0014$ ) * $P<0.01$ compared to control; $\mathrm{P}-\mathrm{P} 70 \mathrm{S6K} 1$ (Diet $\mathrm{F}(1,8)=7.89, P=0.022$ ) with post hoc Tukey's test with interaction between sex and diet. * $P<0.05$ compared to control in pWAT. For p-AKT in gWAT $(\operatorname{Sex} F(1,8)=7.51$, $P=0.02$ ). One-way ANOVA with post hoc Tukey's test $* P<0.008$ compared to control.

suggested by evidence from studies using $\alpha$ ERKO and $\beta E R K O$ mice exposed to streptozotocin, which did not exhibit an increased incidence of diabetes compared to wild-type mice.

These adipose tissue alterations are associated with the development of IR $(13,16,37,38,39)$. Consistently, we observed IR in all animals treated with a HSD. Furthermore, sex-related differences were notable between females and males. Males were less sensitive to insulin than females. In consequence, only the HSD males were hyperglycemic, compared to the controls, while females were more intolerant to glucose. All HSD rats were hyperinsulinemic compared to their controls, as a result of IR; insulin levels were higher in males than in females in both HSD and controls.

During IR, insulin is not acting correctly in its target. Physiologic adaptability in insulin sensitivity is
A
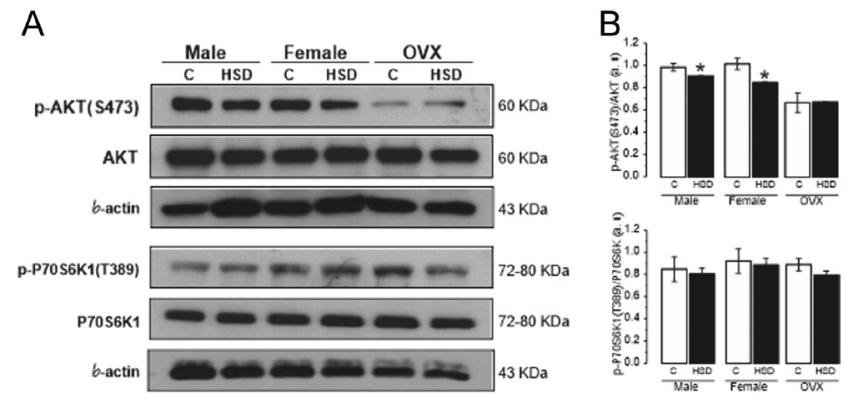

\section{Figure 8}

Effect of high-sucrose diet over the insulin-signaling pathway in gastrocnemius muscle. Representative blots of AKT, p-AKT(S473), P70S6K1, p-P70S6K1(T389) and $\beta$-actin as a load control, from pooled gastrocnemius muscles (A). Normalized ratio of phosphorylated AKT(S473) and P70S6K1(T389) and total forms (B). Mean density \pm S.E.M. from three independent experiments. Two-way ANOVA was performed for p-AKT (Sex, $F(1,4)=0.309, P=0.60$ and diet $F(1,4)=68.92, P=0.001$ ), with post hoc Tukey's test * $P<0.003$ compared to control. With interaction between sex and diet.

an essential mechanism that allow nutrient distribution in the organism under different conditions of energy demand (reviewed in (39)). Moreover, several tissues such as muscle and adipose tissue develop IR during chronic overnutrition preventing nutrient-induced toxicity (40, 41); hence, IR triggers metabolic illness (39).

Insulin receptor activation starts the insulin-signaling pathway. Phosphorylation in tyrosine residues promotes the IRS1 binding and activation/phosphorylation of other kinases in the insulin pathway such as PI3K, AKT, and mTOR kinase. The later kinase regulates anabolic and mitogenic processes such as proliferation, growth, and survival through several effectors (42).

A well-documented mechanism suggests that mTOR and its downstream target, the ribosomal protein S6 kinase 1(S6K1 or P70S6K1) participates in the obesity-induced IR $(21,43,44,45,46)$, since S6K1 deficient mice (S6K1-/-) were protected from diet-induced IR (46). Obesity and cytokines promote mTOR activation and the subsequent phosphorylation of S6K1 on threonine 389 (47), which inhibits insulin signaling through phosphorylation of IRS1 on Ser1101 and the consequent reduction of the PI3K/AKT activation (21).

Interestingly, in our study, we observed bands of the total IRS1 protein in HSD male, female, and OVX groups, with the latest showing the lowest protein levels. However, IRS1 was undetectable in the adipose tissue of all control groups. It is probable that during fasting conditions in healthy rats, an inactive state of the insulinsignaling pathway with shallow levels of IRS could be observed. In contrast, during an insulin resistant state, hyperinsulinemia and hyperglycemia constantly activate

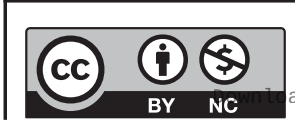

This work is licensed under a Creative Commons Attribution-NonCommercial 4.0 International License. ded from Bioscientifica.com at 04/26/2023 11:31:24AM 
the insulin signaling pathway in a dysregulated fashion even during fasting conditions (48).

Furthermore, p-IRS1(Ser1101) levels were undetectable in pWAT, gWAT, and gastrocnemius, suggesting that phosphorylation on serine 1101 is not an essential molecular mechanism in our model, despite it is the most documented site involved in the downregulation of IRS1 by S6K1 (21). Several inhibitory serine and threonine phosphorylation sites on IRS may impair insulin signaling. For example, IRS1 phosphorylation on serine 522 inhibits this signalling. Furthermore, decreasing the AKT expression with siRNA decreased the IRS1 phosphorylation on serine 522, suggesting that the PI3K/AKT signaling is involved in the phosphorylation of this site (49).

However to discard any problem with the antibody used in our experiments, we performed a blot using gWAT samples of 20 days old male rats as positive controls where we observed a band of p-IRS1(Ser1101) (Supplementary Figs 1 and 2).

We observed that p-AKT(S473)/AKT ratio on pWAT was higher in HSD males and females compared to their controls, indicating that the pathway is more active at this point. However, an unexpected reduction in p-P70S6K1(Thr389)/P70S6K1 levels in HSD males and OVXs rats suggests impaired signaling downstream of AKT due to a decreased activation of the mTORC1, which results in a decreased P70S6K1 phosphorylation, females did not show any change.

We also observed a reduction in the p-AKT(S473) levels in gWAT, but only in HSD females. This alteration seems to affect other pathways downstream of AKT but was not related to S6K1 as it was revealed by the p-S6K1(Thr389) levels. In the gastrocnemius muscle, we observed the same effect that in gWAT, a decrease in the p-AKT levels in both HSD sexes without changes in p-S6K1. These results indicate that the molecular mechanisms of IR in MS are tissue-specific and sex-associated.

Tissue-specific insulin sensitivity has been informed in some reports. Moreover, adipose tissue insulin resistance has been proposed as the triggering process for the development of systemic insulin resistance (48). Furthermore, sex differences have been reported in insulin sensitivity in the intra-abdominal adipose tissue, which may be regulated by physiological levels of sex steroids. Adipocytes from females show increased insulin sensitivity and lipogenesis compared to males adipocytes. That could partially explain why women are more sensitive to insulin, although women have higher adiposity compared to men (50).
This work explored the effects of a diet with high sucrose in a Wistar rat model; these animals do not have a genetic susceptibility to develop obesity or diabetes. Other studies include a high-fat diet or cafeteria diet, where other metabolic effects can be observed. Moreover, we measured factors associated with critical nodes in insulin signaling; however, other molecules could also be altered.

In summary, high-sucrose diet induced MS in rats, in a different way between sexes. Insulin resistance mechanisms were sex-related; and showed a tissue-specific pattern. Finally, HSD induced more severe changes in male than in the female rats.

\section{Supplementary materials}

This is linked to the online version of the paper at https://doi.org/10.1530/ EC-20-0288.

\section{Declaration of interest}

The authors declare that there is no conflict of interest that could be perceived as prejudicing the impartiality of the research reported.

\section{Funding}

This work was supported by DGAPA-PAPIIT (IN208720) and CONACYT (CB253222) to Marcia Hiriart, and DGAPA-PAPIIT (IN210118) to Myrian Velasco.

\section{Author contribution statement}

$\mathrm{V} M$ carried out the experiments, participated in design of the experiments and writing the manuscript. $\mathrm{OH} \mathrm{R} \mathrm{I} \mathrm{carried} \mathrm{out} \mathrm{western} \mathrm{blot} \mathrm{experiments,}$ $L C$ carried out insulin quantitation and writing the manuscript, S Z Y I carried out cytokines quantification, R Y J carried out adipocytes diameter from male rats, $\mathrm{M} \mathrm{H}$ designed experiments, writing the manuscript. All authors read and approved the final manuscript.

\section{Acknowledgements}

The authors are grateful to Carmen Sánchez-Soto for technical assistance, Claudia V Rivera Cerecedo, Héctor A Malagón Rivero and Gabriela Xóchitl Ayala Méndez from the Animal House Unit of Instituto de Fisiología Celular IFC UNAM, for assistance in performing the surgery to take the ovaries from the rats, and in blood pressure experiments. Sandra Daniela Rodríguez Montaño from Histology Unit IFC UNAM for assistance with histological processing. Ana Ma. Escalante, Daniel Macouzet Iturbe, and Francisco Pérez Eugenio from the Computer Unit, IFC, UNAM.

\section{References}

1 Deng $\mathrm{H} \&$ Jasper H. Sexual dimorphism: how female cells win the race. Current Biology 201626 R212-R215. (https://doi.org/10.1016/j. cub.2016.01.062)

2 Vige A, Gallou-Kabani C \& Junien C. Sexual dimorphism in nonMendelian inheritance. Pediatric Research 200863 340-347. (https:// doi.org/10.1203/PDR.0b013e318165b896)

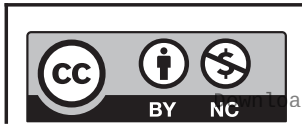

This work is licensed under a Creative Commons Attribution-NonCommercial 4.0 International License. ded from Bioscientifica.com at 04/26/2023 11:31:24AM 
3 Moller DE \& Flier JS. Insulin resistance-mechanisms, syndromes, and implications. New England Journal of Medicine 1991325 938-948. (https://doi.org/10.1056/NEJM199109263251307)

4 Kautzky-Willer A, Harreiter J \& Pacini G. Sex and gender differences in risk, pathophysiology and complications of type 2 diabetes mellitus. Endocrine Reviews 201637 278-316. (https://doi. org/10.1210/er.2015-1137)

5 Hiriart M, Velasco M, Larque C \& Diaz-Garcia CM. Metabolic syndrome and ionic channels in pancreatic beta cells. Vitamins and Hormones 2014 95 87-114. (https://doi.org/10.1016/B978-0-12-800174-5.00004-1)

6 Samson SL \& Garber AJ. Metabolic syndrome. Endocrinology and Metabolism Clinics of North America 201443 1-23. (https://doi. org/10.1016/j.ecl.2013.09.009)

7 Garvey WT, Mechanick JI, Brett EM, Garber AJ, Hurley DL, Jastreboff AM, Nadolsky K, Pessah-Pollack R, Plodkowski R \& Reviewers of the AACE/ACE Obesity Clinical Practice Guidelines. American Association of Clinical Endocrinologists and American College of Endocrinology Comprehensive Clinical Practice guidelines for medical care of patients with obesity executive summary complete guidelines. Endocrine Practice 201622 842-884. (https://doi. org/10.4158/EP161356.ESGL)

8 Larque C, Velasco M, Navarro-Tableros V, Duhne M, Aguirre J, Gutierrez-Reyes G, Moreno J, Robles-Diaz G, Hong E \& Hiriart M. Early endocrine and molecular changes in metabolic syndrome models. IUBMB Life 201163 831-839. (https://doi.org/10.1002/iub.544)

9 Rochlani Y, Pothineni NV \& Mehta JL. Metabolic syndrome: does it differ between women and men? Cardiovascular Drugs and Therapy 201529 329-338. (https://doi.org/10.1007/s10557-015-6593-6)

10 Garaulet M, Perex-Llamas F, Fuente T, Zamora S \& Tebar FJ. Anthropometric, computed tomography and fat cell data in an obese population: relationship with insulin, leptin, tumor necrosis factoralpha, sex hormone-binding globulin and sex hormones. European Journal of Endocrinology 2000143 657-666. (https://doi.org/10.1530/ eje.0.1430657)

11 Karastergiou K \& Fried SK. Cellular mechanisms driving sex differences in adipose tissue biology and body shape in humans and mouse models. Advances in Experimental Medicine and Biology 2017 1043 29-51. (https://doi.org/10.1007/978-3-319-70178-3_3)

12 Karastergiou K, Smith SR, Greenberg AS \& Fried SK. Sex differences in human adipose tissues - the biology of pear shape. Biology of Sex Differences 20123 13. (https://doi.org/10.1186/2042-6410-3-13)

13 Gregor MF \& Hotamisligil GS. Inflammatory mechanisms in obesity. Annual Review of Immunology 201129 415-445. (https://doi. org/10.1146/annurev-immunol-031210-101322)

14 Maury E \& Brichard SM. Adipokine dysregulation, adipose tissue inflammation and metabolic syndrome. Molecular and Cellular Endocrinology 2010314 1-16. (https://doi.org/10.1016/j. mce.2009.07.031)

15 Schoettl T, Fischer IP \& Ussar S. Heterogeneity of adipose tissue in development and metabolic function. Journal of Experimental Biology 2018221 (Pt Supplement 1) jeb162958. (https://doi.org/10.1242/ jeb.162958)

16 Grundy SM. Metabolic syndrome update. Trends in Cardiovascular Medicine 201626 364-373. (https://doi.org/10.1016/j. tcm.2015.10.004)

17 Muoio DM \& Newgard CB. Mechanisms of disease:molecular and metabolic mechanisms of insulin resistance and beta-cell failure in type 2 diabetes. Nature Reviews: Molecular Cell Biology 20089 193-205. (https://doi.org/10.1038/nrm2327)

18 Taniguchi CM, Emanuelli B \& Kahn CR. Critical nodes in signalling pathways: insights into insulin action. Nature Reviews: Molecular Cell Biology 20067 85-96. (https://doi.org/10.1038/nrm1837)

19 Haeusler RA, McGraw TE \& Accili D. Biochemical and cellular properties of insulin receptor signalling. Nature Reviews: Molecular Cell Biology 201819 31-44. (https://doi.org/10.1038/nrm.2017.89)
20 Catalan V, Gomez-Ambrosi J, Rodriguez A, Ramirez B, Andrada P, Rotellar F, Valenti V, Moncada R, Marti P, Silva C et al. Expression of $\mathrm{S} 6 \mathrm{~K} 1$ in human visceral adipose tissue is upregulated in obesity and related to insulin resistance and inflammation. Acta Diabetologica 201552 257-266. (https://doi.org/10.1007/s00592-014-0632-9)

21 Tremblay F, Brule S, Hee Um S, Li Y, Masuda K, Roden M, Sun XJ, Krebs M, Polakiewicz RD, Thomas G et al. Identification of IRS-1 Ser-1101 as a target of S6K1 in nutrient- and obesity-induced insulin resistance Ser. PNAS 2007104 14056-14061. (https://doi. org/10.1073/pnas.0706517104)

22 Unwin N, Shaw J, Zimmet P \& Alberti KG. Impaired glucose tolerance and impaired fasting glycaemia: the current status on definition and intervention. Diabetic Medicine 200219 708-723. (https://doi.org/10.1046/j.1464-5491.2002.00835.x)

23 Velasco M, Larque C, Gutierrez-Reyes G, Arredondo R, SanchezSoto C \& Hiriart M. Metabolic syndrome induces changes in KATPchannels and calcium currents in pancreatic beta-cells. Islets 20124 302-311. (https://doi.org/10.4161/isl.21374)

24 Velasco M, Larque C, Diaz-Garcia CM, Sanchez-Soto C \& Hiriart M. Rat pancreatic beta-cell culture. Methods in Molecular Biology 2018 1727 261-273. (https://doi.org/10.1007/978-1-4939-7571-6_20)

25 Gallagher D, Heymsfield SB, Heo M, Jebb SA, Murgatroyd PR \& Sakamoto Y. Healthy percentage body fat ranges: an approach for developing guidelines based on body mass index. American Journal of Clinical Nutrition 200072 694-701. (https://doi.org/10.1093/ ajcn/72.3.694)

26 Palmer BF \& Clegg DJ. The sexual dimorphism of obesity. Molecular and Cellular Endocrinology 2015402 113-119. (https://doi. org/10.1016/j.mce.2014.11.029)

27 Alberti KG, Eckel RH, Grundy SM, Zimmet PZ, Cleeman JI, Donato KA, Fruchart JC, James WP, Loria CM, Smith SC, Jr et al. Harmonizing the metabolic syndrome: a joint interim statement of the International Diabetes Federation Task Force on Epidemiology and Prevention; National Heart, Lung, and Blood Institute; American Heart Association; World Heart Federation; International Atherosclerosis Society; and International Association for the Study of Obesity. Circulation 2009120 1640-1645. (https://doi. org/10.1161/CIRCULATIONAHA.109.192644)

28 Grundy SM, Brewer HB, Jr, Cleeman JI, Smith SC, Jr, Lenfant C, American Heart Association \& National Heart, Lung, and Blood Institute. Definition of metabolic syndrome: report of the National Heart, Lung, and Blood Institute/American Heart Association conference on scientific issues related to definition. Circulation 2004109 433-438. (https://doi.org/10.1161/01.CIR.0000111245.75752.C6)

29 Park A, Kim WK \& Bae KH. Distinction of white, beige and brown adipocytes derived from mesenchymal stem cells. World Journal of Stem Cells 20146 33-42. (https://doi.org/10.4252/wjsc.v6.i1.33)

30 Gonzalez-Muniesa P, Martinez-Gonzalez MA, Hu FB, Despres JP, Matsuzawa Y, Loos RJF, Moreno LA, Bray GA \& Martinez JA. Obesity. Nature Reviews: Disease Primers 20173 17034. (https://doi. org/10.1038/nrdp.2017.34)

31 Halberg N, Wernstedt-Asterholm I \& Scherer PE. The adipocyte as an endocrine cell. Endocrinology and Metabolism Clinics of North America 200837 753-768, x-xi. (https://doi.org/10.1016/j.ecl.2008.07.002)

32 Cooke PS \& Naaz A. Role of estrogens in adipocyte development and function. Experimental Biology and Medicine 2004229 1127-1135. (https://doi.org/10.1177/153537020422901107)

33 Wade GN, Gray JM \& Bartness TJ. Gonadal influences on adiposity. International Journal of Obesity 19859 (Supplement 1) 83-92.

34 Leeners B, Geary N, Tobler PN \& Asarian L. Ovarian hormones and obesity. Human Reproduction Update 201723 300-321. (https://doi. org/10.1093/humupd/dmw045)

35 Palmisano BT, Zhu L, Eckel RH \& Stafford JM. Sex differences in lipid and lipoprotein metabolism. Molecular Metabolism 201815 45-55. (https://doi.org/10.1016/j.molmet.2018.05.008) https://ec.bioscientifica.com https://doi.org/10.1530/EC-20-0288 (c) 2020 The authors Published by Bioscientifica Ltd

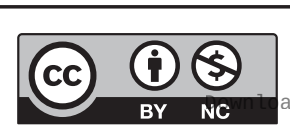

This work is licensed under a Creative Commons Attribution-NonCommercial 4.0 International License. ded from Bioscientifica.com at 04/26/2023 11:31:24AM 
36 Romero-Aleshire MJ, Diamond-Stanic MK, Hasty AH, Hoyer PB \& Brooks HL. Loss of ovarian function in the VCD mouse-model of menopause leads to insulin resistance and a rapid progression into the metabolic syndrome. American Journal of Physiology: Regulatory Integrative and Comparative Physiology 2009297 R587-R592. (https:// doi.org/10.1152/ajpregu.90762.2008)

37 Adams-Huet B, Devaraj S, Siegel D \& Jialal I. Increased adipose tissue insulin resistance in metabolic syndrome: relationship to circulating adipokines. Metabolic Syndrome and Related Disorders 201412 503-507. (https://doi.org/10.1089/met.2014.0092)

38 Kern L, Mittenbuhler MJ, Vesting AJ, Ostermann AL, Wunderlich CM \& Wunderlich FT. Obesity-induced TNFalpha and IL-6 signaling: the missing link between obesity and inflammation-driven liver and colorectal cancers. Cancers 201811 24. (https://doi.org/10.3390/ cancers11010024)

39 Nolan CJ \& Prentki M. Insulin resistance and insulin hypersecretion in the metabolic syndrome and type 2 diabetes: time for a conceptual framework shift. Diabetes and Vascular Disease Research 201916 118-127. (https://doi.org/10.1177/1479164119827611)

40 Nolan CJ, Ruderman NB, Kahn SE, Pedersen O \& Prentki M. Insulin resistance as a physiological defense against metabolic stress: implications for the management of subsets of type 2 diabetes. Diabetes 201564 673-686. (https://doi.org/10.2337/db14-0694)

41 Nolan CJ, Ruderman NB \& Prentki M. Intensive insulin for type 2 diabetes: the risk of causing harm. Lancet: Diabetes and Endocrinology 20131 9-10. (https://doi.org/10.1016/S2213-8587(13)70027-5)

42 Saxton RA \& Sabatini DM. MTOR signaling in growth, metabolism, and disease. Cell 2017168 960-976. (https://doi.org/10.1016/j. cell.2017.02.004)

43 Dann SG, Selvaraj A \& Thomas G. mTOR Complex1-S6K1 signaling: at the crossroads of obesity, diabetes and cancer.
Trends in Molecular Medicine 200713 252-259. (https://doi. org/10.1016/j.molmed.2007.04.002)

44 Laplante M \& Sabatini DM. MTOR signaling in growth control and disease. Cell 2012149 274-293. (https://doi.org/10.1016/j. cell.2012.03.017)

45 Um SH, D'Alessio D \& Thomas G. Nutrient overload, insulin resistance, and ribosomal protein S6 kinase 1, S6K1. Cell Metabolism 20063 393-402. (https://doi.org/10.1016/j. cmet.2006.05.003)

46 Um SH, Frigerio F, Watanabe M, Picard F, Joaquin M, Sticker M, Fumagalli S, Allegrini PR, Kozma SC, Auwerx J et al. Absence of S6K1 protects against age- and diet-induced obesity while enhancing insulin sensitivity. Nature 2004431 200-205. (https://doi. org/10.1038/nature02866)

47 Moreno-Navarrete JM, Ortega F, Sanchez-Garrido MÁ, Sabater M, Ricart W, Zorzano A, Tena-Sempere M \& Fernandez-Real JM. Phosphorylated S6K1 (Thr389) is a molecular adipose tissue marker of altered glucose tolerance. Journal of Nutritional Biochemistry 201324 32-38. (https://doi.org/10.1016/j. jnutbio.2012.01.005)

48 Tan SX, Fisher-Wellman KH, Fazakerley DJ, Ng Y, Pant H, Li J, Meoli CC, Coster AC, Stockli J \& James DE. Selective insulin resistance in adipocytes. Journal of Biological Chemistry 2015290 11337-11348. (https://doi.org/10.1074/jbc.M114.623686)

49 Giraud J, Haas M, Feener EP, Copps KD, Dong X, Dunn SL \& White MF. Phosphorylation of Irs1 at SER-522 inhibits insulin signaling. Molecular Endocrinology 200721 2294-2302. (https://doi. org/10.1210/me.2007-0159)

50 Macotela Y, Boucher J, Tran TT \& Kahn CR. Sex and depot differences in adipocyte insulin sensitivity and glucose metabolism. Diabetes 200958 803-812. (https://doi.org/10.2337/db08-1054)

Received in final form 11 August 2020

Accepted 14 August 2020

Accepted Manuscript published online 14 August 2020
This work is licensed under a Creative Commons Attribution-NonCommercial 4.0 International License. ded from Bioscientifica.com at 04/26/2023 11:31:24AM 